\title{
G4.5 Pamam Dendrimer-Risperidone: Biodistribution and Behavioral Changes in In Vivo Model
}

Maria Jimena Prieto ${ }^{1,2^{*}}$, Nahuel Eduardo del Rio Zabala1,2, Cristian Hernán Marotta ${ }^{1,2}$, Dario Bichara ${ }^{3}$, Sergio Simonetta ${ }^{3}$, Nadia Silvia

Chiaramoni $^{1,2}$ and Silvia del Valle Alonso ${ }^{1,2}$

${ }^{1}$ Department of Science and Technology, National University of Quilmes, Argentina

2IMBICE-CONICET, Argentina

${ }^{3}$ Leloir Institute Foundation, Argentina

\begin{abstract}
Dendritic polymers are considered as emerging and outstanding carriers as modern medicinal systems due to their derivatisable branched architecture and possibility to modify them in numerous ways. Here, G4.5 PAMAM dendrimers were obtained as carriers of the antipsychotic drug risperidone. Despite their extensive applicability in the pharmaceutical field, the use of dendrimers as carriers in biological systems is constrained due to their inherent associated toxicity. The biocompatibility of dendrimers and dendrimer-risperidone complexes was evaluated in vivo for biological performance. To this end, the pharmacokinetics and biodistribution after oral treatment of free risperidone and dendrimer-risperidone complexes were studied in healthy mice. Also, the behavioral changes such as locomotion, aggression, dominance in male and female mice were evaluated both after a single dose and after daily therapy for 8 days. Also, in vivo effects of risperidone and dendrimer-risperidone complexes on the locomotion of zebrafish larvae were explored.
\end{abstract}

The data obtained suggest that the unmetabolized risperidone complexes increase the arrival to the brain after 90 minutes. On the other hand, behavioral studies showed an increase in the potency of the drug in animals treated with the complexes.

Keywords: G4.5 Pamam; Locomotor; Risp; Zebrafish

\section{Introduction}

The antipsychotic drug risperidone, 3-[2-[4-(6-fluoro-1,2benzisoxazol-3-yl)-1-piperidinyl] ethyl]-6,7,8,9-tetrahydro-2-methyl$4 \mathrm{H}$-pyrido[1,2-a] pyrimidin-4-one (Risp), belongs to the chemical class of benzisoxazoles and is one of the most widely used drugs in the treatment of autism spectrum disorders (ASD) [1,2]. ASD, which occur in 1 out of 150 individuals [1], include different neurodevelopment disorders that manifest mainly in the earlier years of life [3], affecting language, communication and reciprocal social interaction development [4]. Risp has low solubility in aqueous medium and, when orally administered, exhibits low bioavailability due to extensive firstpass metabolism and high protein binding (>90\%) [5]. Moreover, nontargeted delivery usually results in numerous side effects. Since Risp target organ is the brain, it is necessary not only to develop a strategy to improve drug bioavailability, by avoiding first-pass metabolism, but also to achieve desired drug concentration at the site of action, thus reducing undesirable side effects [2].

In the last years, strategies with chemical therapies, particularly the design of nano-structured drug carrier systems [6], have been proposed to overcome these issues regarding ASD treatment. However, these kinds of carriers (plain, ultradeformable, stealth, $\mathrm{pH}$-sensitive liposomes, immunoliposomes, nanoparticles and dendrimers) must be carefully designed and/or chosen because their pharmacokinetics, biodistribution, and tissue selectivity will exclusively depend on the nanocarrier's structure [2,7-9]. In the last years, PAMAM dendrimers have been found to be useful to improve the solubility of low aqueous soluble drugs $[10,11]$, so our previous work aimed to enhance Risp solubility, by means of PAMAM dendrimers [12].

In the present study, we studied the biodistribution and pharmacokinetics of the free Risp and DG4.5-Risp complexes given orally to healthy BALB/C mice. Behavioral studies were performed in healthy mice and toxicity studies in the zebrafish animal model. These studies were conducted to evaluate the potency of treatment with DG4.5-Risp complexes compared to the free Risp and the possible reduction of side effects seen in the traditional treatment.

\section{Material and Methods}

\section{Preparation of DG4.5-Risp Complexes}

Complexes were prepared as described before in Prieto et al. [12].

\section{Animals}

\section{Biodistribution and pharmacokinetics}

Biodistribution and pharmacokinetics of Risp, were carried out by administering free Risp or DG4.5-Risp using BALB/C (25 g - $30 \mathrm{~g})$ of the National University of Quilmes (Buenos Aires, Argentina).The animals were kept at $24 \pm 1^{\circ} \mathrm{C}$ and $60-70 \%$ humidity, with light-dark cycles of $12 \mathrm{~h}$, in stainless steel boxes. The animals were given tap water to drink and food ad libitum.

\section{Behavioral test}

Mice: Male and female 8-15-week-old BALB/C mice were used

*Corresponding author: Maria Jimena Prieto, Department of Science and Technology, National University of Quilmes, Argentina, Tel: +54 1143657100, Ext 4323; Fax: +54 1143657132; E-mail: jprieto@unq.edu.ar

Received November 13, 2013; Accepted December 18, 2013; Published December 20, 2013

Citation: Prieto MJ, del Rio Zabala NE, Marotta CH, Bichara D, Simonetta S et al. (2013) G4.5 Pamam Dendrimer-Risperidone: Biodistribution and Behavioral Changes in In Vivo Model. J Nanomedine Biotherapeutic Discov 4: 121 doi:10.4172/2155-983X.1000121

Copyright: $\odot 2013$ Prieto MJ, et al. This is an open-access article distributed under the terms of the Creative Commons Attribution License, which permits unrestricted use, distribution, and reproduction in any medium, provided the original author and source are credited. 
for behavioral tests. Animals of the same treatment, sex and age were housed in stainless steel cages, in a room under controlled temperature $\left(24 \pm 3^{\circ} \mathrm{C}\right)$, relative humidity $(60-70 \%)$ and a $12 \mathrm{~h} \mathrm{light/dark} \mathrm{cycle.} \mathrm{Food}$ and water were available ad libitum. All efforts were made to minimize the number of animals and their suffering. Both acute and chronic treatment experiments were conducted on the same animals.

Zebrafish: A breeding stock of heterogeneous wild type zebrafish was purchased from a local pet shop and inbred in our facility, as described previously Kimmel et al. [13]. Sexually mature females and males (8-12 months old) were kept at a ratio of 3:1 in a glass aquarium filled with filtered tap water at $26 \pm 1{ }^{\circ} \mathrm{C}$ under 14 hour day/night light regime (lights $\mathrm{ON}=$ Zeitgeber Time zero (ZT0)). Fishes were fed with dry flakes (TetraMin PRO') twice per day and with nauplia larvae of Artemia once a day ad libitum. For embryo production, four females and two males were crossed the night before the spawning day in traps made of plastic mesh, to prevent the eggs from cannibalism. Green algae and glass marbles were also added as spawning substrate. Collected eggs were maintained in a petri dish with $\mathrm{E} 3$ saline embryo medium $\left(5 \mathrm{mM} \mathrm{NaCl}, 0.17 \mathrm{mM} \mathrm{KCl}, 0.33 \mathrm{mM} \mathrm{CaCl}_{2}\right.$, and $0.33 \mathrm{mM} \mathrm{Mg} \mathrm{SO}_{4}$ ) at $28.5^{\circ} \mathrm{C}$, and examined for fertilization under a Nikkon TN-PSE80 stereomicroscope. Non-fertilized eggs were discarded.

\section{Biodistribution and Pharmacokinetics}

Treatment: The treatment was achieved by keeping the animals deprived of water $10 \mathrm{~h}$ before each test and using a gastric tube designed ad hoc by the working group. The maximum volume of treatment was $50 \mu$ l. The maximum dose administered was $100 \mu \mathrm{g}$ Risp, either in the free form or as complexes. The dose was selected as the recommended dosage for human treatment, being of $1.5 \mathrm{mg}$ of drug per kilogram weight/individual (for individuals weighing less than $20 \mathrm{~kg}$ ). We also considered the method detection limit and recovery percentage of the purification method.

Pharmacokinetics: Pharmacokinetic parameters of free Risp or complexes were obtained after oral treatment of a single dose of i) free Risp ii) DG4.5-Risp and iii) PBS as control. Group of animals $(n=6)$ were used for each of the following times: 2, 5, 15, 30, 60 and $90 \mathrm{~min}$. After 60 or $90 \mathrm{~min}$, the animals were anesthetized and then sacrificed by cervical dislocation.

At predetermined times post-treatment, the animals were anesthetized and blood samples were withdrawn from the retro-orbital sinus with heparinized capillaries. Then, the plasma was separated from the red cells by centrifugation for $10 \mathrm{~min}$, at $6000 \times \mathrm{g}$ and stored at $-20^{\circ} \mathrm{C}$ for subsequent extraction and Risp quantitation by Highperformance liquid chromatography (HPLC) [14,15]. Data obtained were corrected taking into account the recovery factor from previous extractions. Animals were anesthetized by inhalation with isoflurane prior to sample collection and sacrifice. Pharmacokinetic curves of Risp concentration $(\mathrm{mg} / \mathrm{ml}$ ) in plasma versus time allowed obtaining the following parameters: AUC, Cmax and tmax; using GraphPad Prism 5.0 software and Microsoft Office Excel 2007.

Biodistribution: After $60 \mathrm{~min}$ or $90 \mathrm{~min}$, the animals were anesthetized and sacrificed by cervical dislocation, their liver, brain and spleen extracted and then each organ washed with saline and weighed. Finally, they were stored at $-20^{\circ} \mathrm{C}$ for subsequent extractions and Risp quantitation by HPLC. Data obtained were corrected taking into account the recovery factor from previous extractions.

\section{Behavioral Test in Mice}

Treatment: Drugs were administered orally, once a day in the mornings, $60 \mathrm{~min}$ before the tests, for eight consecutive days. The net dose of Risp administered (either as free Risp or DG4.5-Risp) was of $1 \mu \mathrm{g}$ of Risp per gram of animal weight, in a concentration of $1 \mu \mathrm{g}$ of $\mathrm{Risp} / \mu \mathrm{l}$ in PBS buffer. Dose selection is based on the daily treatment in humans. Free DG4.5 mass administered corresponds with the DG4.5 mass administered in the DG4.5-Risp complex in a volume of $1 \mu \mathrm{l}$ in PBS per $g$ of animal weight. Controls were given PBS in a dose of $1 \mu \mathrm{l}$ of PBS per $g$ of animal weight.

Behavioral tests: All tests were performed between 10:00 and 12:00 $\mathrm{h}$ in a silent room in controlled conditions of light and temperature (24 $\pm 3^{\circ} \mathrm{C}$ ). All animals were transported to the room 1 hour prior to the tests. Handling was minimal during the tests. Seven male and seven female mice were used for Risp, DG4.5-Risp and control treatments, whereas two males and two females were used for the treatment with DG4.5. Two series of tests were performed: acute, on day 1 of treatment and chronic, on day 8 of treatment. All animals were housed in groups of three or four animals of the same sex, age and treatment. Two days prior to the tests, for both the acute and chronic tests, animals were housed in solitary confinement to increase sociability and interaction. After the tests, animals were housed in community.

The tests were performed $60 \mathrm{~min}$ after treatment, consecutively, from the least to the most stressing test. Each test lasted $5 \mathrm{~min}$. After the end of one test, the animal was immediately placed on the next test. This consecutive arrangement allowed an efficient performance and a minimum decrease in plasma drug levels $[16,17]$. Tests performed in the acute phase were the following: open field, performed first to increase exploration; elevated cross maze, as a measurement of anxiety; locomotion activity in the cage; sociability and social novelty; nest building, performed in the same cage that housed the animal in solitary confinement prior to the tests. The results of these tests were evaluated $24 \mathrm{~h}$ later. The arrangement of the chronic tests was the following: Open field, elevated cross maze, elevated cross maze closed arm return, locomotion activity in cage and sociability and social novelty.

The following tests were recorded in video for further analysis, and to avoid interference by the observers: Elevated cross maze, locomotion in cage and sociability and social novelty. All implementations used were placed in the same position and orientation. After every test, all surfaces in contact with animals were cleaned with alcohol and left to fully dry.

Tests: Open field: Locomotion and exploration were measured using a $64 \times 57 \mathrm{~cm}$ wide cage with $5 \times 5 \mathrm{~cm}$ grid drawn on the floor. The animal was placed in the center of the cage and allowed to explore the arena. The number of quadrants the animal entered in 5 min was recorded. General exploratory activity was evaluated according to previous descriptions $[18,19]$.

Elevated cross maze: This assay is well characterized to measure anxiety-related behaviors in mice [19]. The elevated cross maze has four arms (two open and two enclosed, $50 \times 10 \mathrm{~cm}$ long each) arranged in a cross. The maze is elevated $1 \mathrm{~m}$ from the ground. The animal is placed in the middle of the maze facing an open arm. Activity was recorded for $5 \mathrm{~min}$, and time spent in each arm, as well as entries and explorations into arms were analyzed. An entry into an arm is defined when the four pawns are in the arm, an exploration is defined when the animal sniffs or places two pawns in the center of the maze.

Elevated cross maze closed arm return: This assay was performed only in chronic tests. After the elevated cross maze test, the animal was lifted and placed on the end of an open arm. Time was calculated until the animal entered a closed arm, with a maximum waiting time of $5 \mathrm{~min}$. 
Locomotor activity in cage: Locomotor activity was evaluated in a familiar environment. The animal was placed in the cage that housed it for 2 days. The test was recorded for further analysis of total locomotion distance using ImageJ software. The cage size, distance and relative position of the camera were for the same in all tests. Measurements are relative to the control.

Sociability and social novelty: This assay was used to monitor social and territorial behaviors. After the locomotor test, an unfamiliar animal of the same sex and age, the intruder, was inserted in the cage. The animals used as intruders were housed with animals of the same sex and age and used exclusively for this test.

The interaction was recorded in video. The number of sniffing, crawling over, following, approaching and distancing, dominant hierarchies, aggressive behaviors and attacks were evaluated. Fighting is more common in male than in female mice. If the attacks were too violent, animals were separated.

To evaluate dominant hierarchy, a scoring system of 1 to 10 divided into four groups was formulated. Groups from 1 to 3 presented only following and sniffing. Groups from 4 to 6 presented not only following and sniffing but also crawled over the intruder. Groups from 6 to 8 presented all the above together with bites and attacks. Groups 9 and 10 presented the highest levels of violent attacks and fighting.

Nest building: As a measure of social activity, we evaluated nest building. Male and female mice build nests using various types of materials [20]. Nests are scored for their height, number of entrances, shape, quality, manipulation of materials and localization in the cage. A well-built nest has the shape of a cocoon with walls that house a cave with one or more entrances [21]. Low material handling reflects a low elaborated nest. After completion of the acute tests, $3 \mathrm{~g}$ of commercial cotton was introduced in the cage that housed the animal in solitary confinement, $24 \mathrm{~h}$ later, and the building quality analyzed. The animal was then returned to the community cage.

\section{Behavioral test in zebra fish-toxicity}

Automated measurement of larval activity events: The system is based on an infrared microbeam arrangement that detects light refraction through the zebrafish body, essentially as described elsewhere [22,23]. Animals were placed in 96 well microplates and subjected to illumination with two infrared microbeams per well (100 $\mu \mathrm{m}$ wide and of $880 \mathrm{~nm}$ wavelength each). A transient fluctuation in the signal is generated when larvae move across the light beam and received by a phototransistor array. Light signals output were digitalized by a multichannel ADC system (WMicrotracker, Designplus SRL, Argentina) at a sample rate of 10 samples/sec and 10 bit resolution. Data were acquired with an IBM-PC connected via RS232 protocol and processed by software programmed in MS-Visual Basic. Signal activity events (defined as the times that larvae cross through infrared microbeams) were calculated in real time by detecting small fluctuations in the signal received. Variations greater than 3\% in the signal received (empirically determined threshold) were considered as activity events. Swimming activity was calculated summing up the number of activity events for 15 minutes. Data are reported as the averaged activity event recorded for each microbeam pair \pm SEM.

Treatment: For the treatment, 48-hpf non-hatched zebrafish embryos were placed in each well of a 96-well plate containing E3 medium and incubated for additional $48 \mathrm{~h}$ at $28^{\circ} \mathrm{C}$. At $4 \mathrm{dpf}$, the medium was replaced by $250 \mu \mathrm{l}$ of solutions of the different compounds or E3 (control). For each assay, 12 technical replicates were used for each dilution. Activity events were recorded for $15 \mathrm{~min}$, three times at 4, 5, 6 and $7 \mathrm{dpf}$ after the addition of the compound tested, at room temperature [22].

Ethics Statement: All animal procedures were performed in strict accordance with National Institutes of Health rules for animal care and maintenance. The study protocols were approved by the Universidad Nacional de Quilmes Institutional Animal Care Committee.

\section{Statistical analysis}

Data are presented as mean \pm standard deviation and analyzed by one-way analysis of variance (ANOVA) and Tukey's Multiple Comparison Test using GraphPad Prism v. 5. Only values with $\mathrm{P}<0.05$ were accepted as significant.

\section{Results and Discussion}

\section{Pharmacokinetics}

Risp concentration in plasma after oral treatment of DG4.5-Risp complexes was significantly lower $(\mathrm{P}<0.05)$ than that found after oral treatment of the free Risp (Figure 1). The maximum concentration of Risp in circulation was observed 15 min post- treatment for both the free Risp and the DG4.5-Risp complexes. Regarding this parameter, the Cmax of the DG4.5-Risp complexes decreased 4.5 times compared to the Cmax of free Risp. In addition, the AUC0-90 of the DG4.5-Risp complexes was almost 5 times lower than the AUC0-90 of the free Risp, although the drug dosage administered was the same (Table 1).

\section{Biodistribution}

Although the amount of drug reaching each organ studied was higher for animals administered DG4.5-Risp after $60 \mathrm{~min}$, this difference was not significant $(\mathrm{P}>0.05)$. However, when the biodistribution of the drug concentration was analyzed in the brain at $90 \mathrm{~min}$ post- treatment, the difference observed was quantitatively significant $(\mathrm{P}<0.05)$ (Figure 2).

The high density of surface groups (one amine-group $/ \mathrm{nm}^{2}$ for DG4 and 1.6 carboxylic-groups $/ \mathrm{nm}^{2}$ for DG4.5) combined with a small size ( 4.5 to $5.0 \mathrm{~nm}$ in diameter for DG4-spheres and DG4.5-ellipsoids) gives these dendrimers a large area/volume ratio. This renders dendrimers with an unusual ability to establish surface interactions with cell

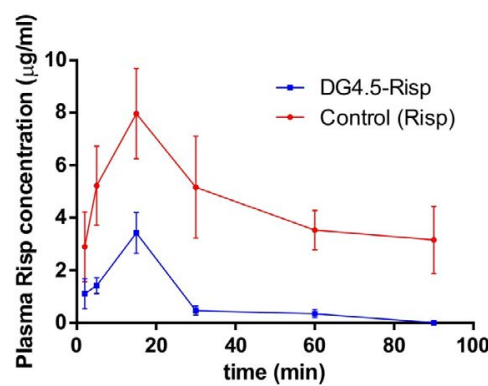

Figure 1: Pharmacokinetics of risperidone in plasma. Blood Concentration of Risperidone versus time $(n=6)$.

\begin{tabular}{|l|c|c|c|}
\hline & $\mathbf{C}_{\text {máx }}(\boldsymbol{\mu} \mathbf{g} / \mathbf{m l})$ & $\mathbf{t}_{\text {máx }}(\mathbf{m i n})$ & AUC $_{\mathbf{0 - 9 0}}(\boldsymbol{\mu} \mathbf{g} / \mathbf{m l} / \mathbf{m i n})$ \\
\hline DG4.5-Risp & $3.42 \pm 0.78$ & 15 & 80,28 \\
\hline Risp & $7.97 \pm 1.72$ & 15 & 395,90 \\
\hline
\end{tabular}

Table 1: Pharmacokinetic parameters after Risp oral treatment in the free form and as the DG4.5-Risp complexes $(n=6)$. 


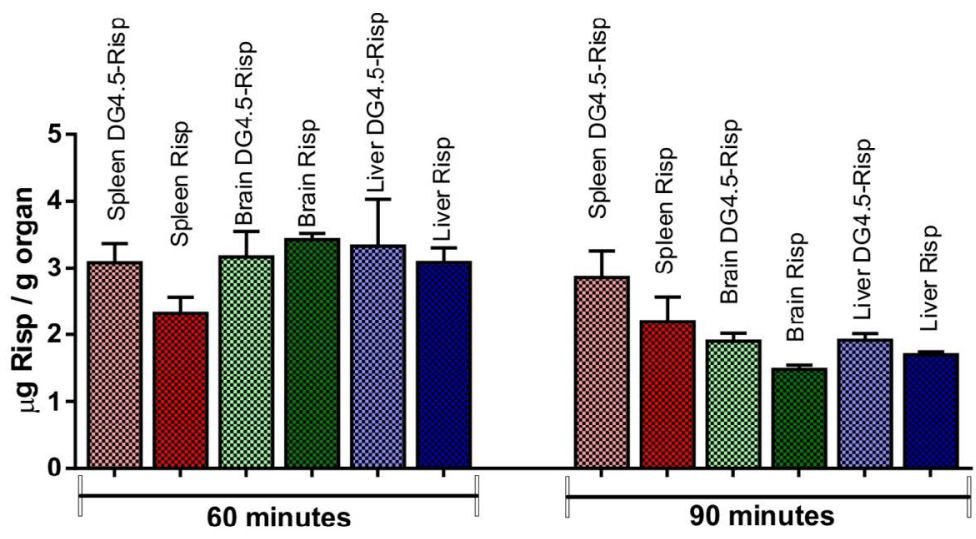

Figure 2: Risperidone drug biodistribution in organs. Risp concentration found for different organs studied after 60 and $90 \mathrm{~min}(\mathrm{n}=6)$.

membranes [24,25]. Besides interacting with membrane lipids [26], the dendrimers possess the ability to modify protein conformation [27]. On the other hand, complexation of Risp with dendrimers could modify their internal volume and hence their size together with the density of surface groups, and it is known that such surface modification changes the interaction between DG4.5 and cells $[28,29]$.

Based on the above conclusions, the pharmacokinetics and biodistribution of the free and complexed Risp were studied in healthy mice, seeking to modify the parameters obtained with the free Risp.

DG4.5-Risp complexes were not orally administered to prove increase absorption of Risp, since it is known that this process is fast and highly efficient (70-90\% of the drug initially administered) [30]. However, an increased plasma level makes the drug more susceptible of being metabolized, generating widespread distribution and decreasing its arrival at the target organ, and hence causing severe side effects. For this reason, we investigated whether Risp, once complexed to DG4.5, could be absorbed by the gastrointestinal tract, and thus show a modified biodistribution and pharmacokinetic profile and if these differential parameters ideally meet the desirable levels for the treatment of non-toxic side effects.

After oral treatment, DG4.5-Risp levels were significantly lower in blood than those of free Risp, when the same dose was administered. This trend was observed for all the pharmacokinetic profiles studied. Furthermore, after 90 min post- treatment, the animals administered with free Risp still exhibited a high level of circulating Risp. This trend was not observed in animals administered DG4.5-Risp and in fact, even after $30 \mathrm{~min}$, these animals showed very low levels of circulating Risp. These are relevant observations because, after coming into circulation, Risp highly binds to plasma proteins and metabolizes with widespread distribution into places where no therapeutic activity is needed.

Continuing with the analysis of the data and results obtained for the pharmacokinetic profile of the drug, it is necessary to consider several factors. First, the complexation of Risp to DG4.5 might have decreased the absorption of the drug. This could be explained by the observed decrease in the circulating Risp concentration, which is also in good agreement with the results obtained by Wiwattanapatapee et al. [31]. More so, flow cytometry and confocal microscopy have shown that DG4.5 cannot be retained by the mucin of the mucosa, because of the anionic macromolecules present in the gut $[7,8]$.

There are few reports concerning the ability of dendrimers to cross the gastrointestinal membrane. Wiwattanapatapee et al. [31] investigated the transport of cationic and anionic dendrimers in the intestine of adult rats, by in vitro assays. Their results suggest that transport through the gut membrane is dependent on electrostatic interactions, and it is influenced by size. They also found that the absorption of the dendrimers of intermediate generations is considerably higher than that of small ones and that dendrimers of smaller generation were transported through third-phase endocytosis.

In contrast, both anionic and cationic dendrimers of generations in between were found to be absorbed by adsorptive endocytosis, either specific or nonspecific. Florence et al. [32] studied the absorption of dendrimers after oral treatment and found that 6 hours post-treatment, the amount of dendrimers accumulated in the stomach, small intestine and large intestine as a whole was $20 \%$ of the initial dose. This author also observed that the incorporation of dendrimers in the small intestine took place preferably through Peyer's patches, while enterocytes played the most important role in the embodiment in the large intestine.

The incorporation of a hydrophobic drug could modify not only the spherical shape of DG4.5 but also its surface groups and/or the charged groups exposed. Thus, the intestinal absorption of the drug would depend on the physicochemical characteristics of the new complex molecule formed. Concerning the biodistribution at $60 \mathrm{~min}$ after oral treatment of the complexes, the amount of drug in the organs analyzed remained almost unchanged compared with the same dose of free Risp. However, the most remarkable result in terms of the biodistribution studies observed in animals administered with the complexes was a significant increase in the drug concentration reaching the brain (white body) 90 minutes post-treatment.

Considering that the chromatographic method can only quantify the unmetabolized drug, the results suggest an increased arrival of dendrimers at the target organ, where DG4.5 act as "protector" of Risp, decreasing its metabolization and consequently the production of 9-OH-Risp. It has been reported that for the treatment with Risp, the drug is metabolized to 9-OH-Risp as a consequence of hydroxylation of the drug by cytochromes CYP2D6 and CYP3A mainly in the liver. This is the most important metabolic pathway and the levels of the Risp dose administered consumed are up to 31\% [33]. Although 9-OHRisp has pharmacological activity, it binds strongly to plasma proteins, decreasing the bioavailability of pharmacologically active components and generating a generalized distribution responsible for many of the side effects of the regular treatment. The main previous results include 
Citation: Prieto MJ, del Rio Zabala NE, Marotta CH, Bichara D, Simonetta S, et al. (2013) G4.5 Pamam Dendrimer-Risperidone: Biodistribution and Behavioral Changes in In Vivo Model. J Nanomedine Biotherapeutic Discov 4: 121. doi:10.4172/2155-983X.1000121

Page 5 of 11

weight gain and hyperprolactinemia [34,35]. Therefore, the proposed alternative of using dendrimers as drug delivery systems to provide protection from enzymatic metabolism is mainly to reduce the side effects of the treatment.

Regarding the dendrimers protective action contributing to the transported molecule, we have previously found that the formulation [8] SDZ-DG4 and SDZ-DG4.5 complexes achieved a reduced metabolism of SDZ by enzymes such as NAT and CYP2C8/9. From this point of view, it would be possible to minimize the generation of toxic hydroxyl products, hence the damage caused by acetylation and hydroxylation, and alterations in enzyme phenotypes that contribute to toxicity if the drug is incorporated into the vehicle.

We were able to modify both the biodistribution and pharmacokinetic parameters of Risp incorporated in anionic DG4.5 transporter. Given these results, the differential profiles observed would establish the basis for an efficient nanosized drug carrier system. This nano-system could improve Risp arrival at its target organ and the protection given by the dendrimers will represent a decrease in the adverse effects of the treatment.

\section{Behavioral}

\section{Behavioral studies in mice}

i. Studies of the Behavior of Mice in their Home-Cage and of their Health in General: The behavior of mice under different treatments was evaluated in their home-cage. As a measurement of activity in the home-cage related to social behavior, we evaluated nest building by adding cotton in each cage. After $24 \mathrm{~h}$ of added material, all mice showed clear evidence of nest building. No physical differences were observed in the fur, general health status and piloerection of moustaches when comparing the results of the different treatments. All animals reacted to external stimuli and had normal visual reflection, and no tardive dyskinesia was observed. The results of free dendrimers tests are not shown because they were identical to those administered with PBS.

ii. Outfield: The exploratory locomotion shown by the animals administered PBS was much higher than that for both treatments with Risp ( $\mathrm{p}<0.05)$. A decrease in the exploratory locomotion was observed in females treated with the complexes, both in the acute and chronic treatments, with respect to the free Risp. This was not the case for males treated with the complexes, which presented the same exploratory activity as those treated with the free drug (Figures 3 and 4).

iii. Elevated Cross Maze: Anxiety was evaluated based on the location of the animal in the maze. A greater amount of time in the open arm is taken as low anxiety, whereas an animal that spends most of the time in the closed arm reflects higher levels of anxiety. This was used to describe the animal as anxious or not anxious. Although the degree of anxiety in mice of both treatments was significantly lower than that of controls, no significant differences were observed between those treated with the free drug and those treated with the complex
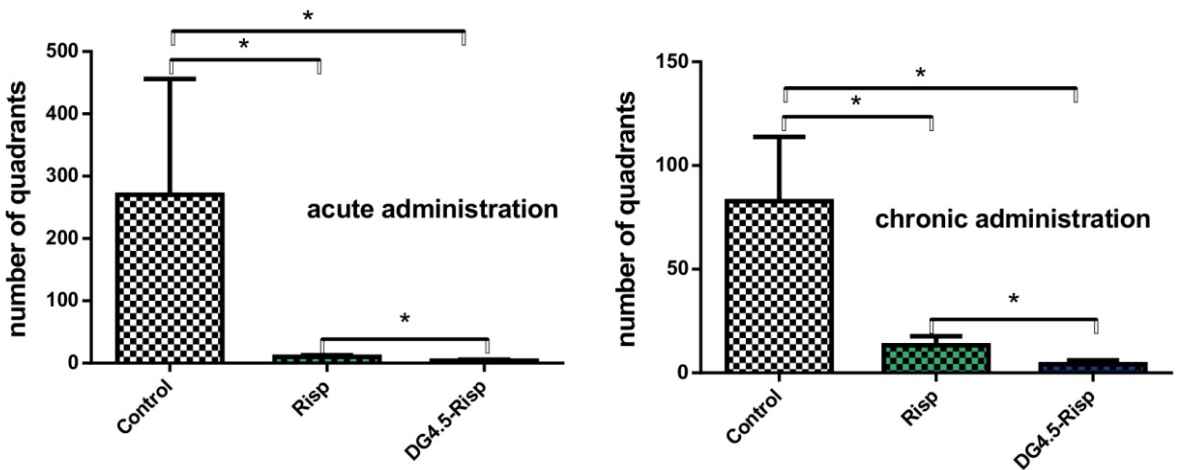

Figure 3: Outfield. Behavioral Studies in Mice with acute and chronic administration. Number of quadrants traversed in the outfield by female mice $(\mathrm{n}=7) .{ }^{*} \mathrm{p}<0.05,{ }^{* \star}$ $p<0.01$.
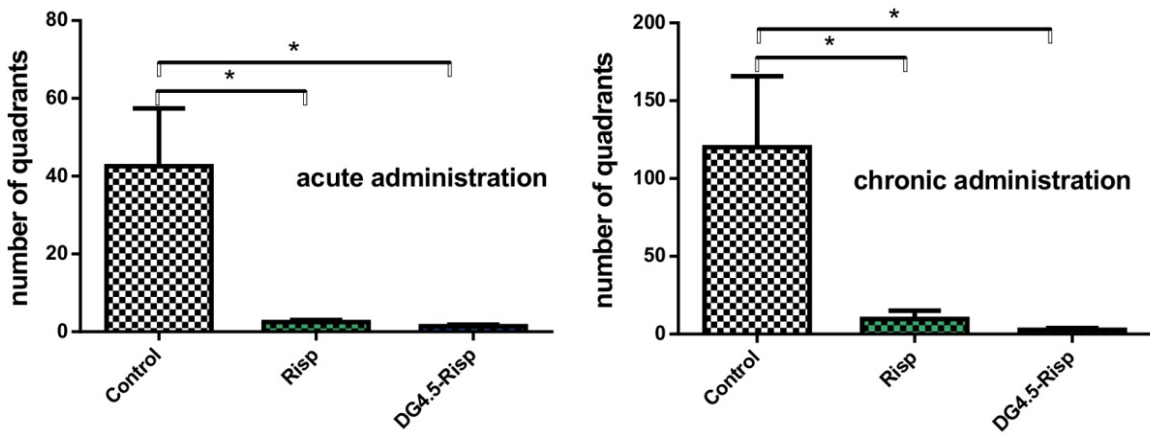

Figure 4: Outfield. Behavioral Studies in Mice with acute and chronic administration. Number of quadrants traversed in the outfield by male mice $(\mathrm{n}=7) .{ }^{*} \mathrm{p}<0.05,{ }^{* *}$ p $<0.01$ 
Citation: Prieto MJ, del Rio Zabala NE, Marotta CH, Bichara D, Simonetta S, et al. (2013) G4.5 Pamam Dendrimer-Risperidone: Biodistribution and Behavioral Changes in In Vivo Model. J Nanomedine Biotherapeutic Discov 4: 121. doi:10.4172/2155-983X.1000121

Page 6 of 11

(Table 2).

iv. Inspections: Regarding inspections in the maze, females under the acute treatment showed $60 \%$ of inspections, against $0 \%$ observed in mice treated with Risp and DG4.5-Risp. Regarding females under the chronic treatment, $71 \%$ of the control group, $43 \%$ of mice treated with Risp and $57 \%$ of mice treated with DG4.5-Risp showed inspection behavior. These results show a greater tendency of inspection in the animals chronically treated with the DG4.5-Risp complex (Table 3).

Regarding male control animals under the acute treatment, $51 \%$ showed inspection behavior compared to $14 \%$ of those treated with Risp or DG4.5-Risp. In those under the chronic treatment, the number of inspections performed by control animals was of $100 \%$, and $28 \%$ and $14 \%$ of the male animals treated with Risp and DG4.5-Risp complexes

\begin{tabular}{|l|c|c|c|c|c|c|}
\hline & \multicolumn{5}{|c|}{ \% of animals showed anxiety } \\
\hline & \multicolumn{3}{|c|}{ Males } & \multicolumn{3}{c|}{ Female } \\
\hline & Control & Risp & DG4.5-Risp & Control & Risp & DG4.5-Risp \\
\hline Acute & 86 & 28 & 28 & 60 & 28 & 14 \\
\hline Chronic & 100 & 43 & 43 & 100 & 71 & 86 \\
\hline
\end{tabular}

Table 2: Percentage of male and female animals referred to all that experimented anxiety in the elevated cross maze. Animals that remained permanently in a closed area were considered anxious $(n=7)$.

\begin{tabular}{|l|c|c|c|c|c|c|}
\hline & \multicolumn{5}{|c|}{$\%$ animals showed inspection behavior } \\
\hline & \multicolumn{5}{|c|}{ Males } & \multicolumn{3}{c|}{ Female } \\
\hline & Control & Risp & DG4.5-Risp & Control & Risp & DG4.5-Risp \\
\hline Acute & 51 & 14 & 14 & 60 & 0 & 0 \\
\hline Chronic & 100 & 28 & 14 & 71 & 43 & 57 \\
\hline
\end{tabular}

Table 3: Percentage of females and males that performed inspections in the elevated cross maze $(n=7)$ showed inspection behavior, in contrast to that observed in females (Table 3).

Comparing genders, we observed that in the acute treatments with Risp and DG4.5-Risp males performed significantly more inspections than females, whereas in the chronic treatments, control males showed significantly more inspections than females, while for Risp and DG4.5-Risp treatments, males showed a smaller fraction of performed inspections than females.

v. Entries: Females of both treatments did not enter the center of the maze or in the open arm area (results not shown). In the acute test, control males did not enter the center of the maze (results not shown). In the case of chronic tests, although no significant differences were found, controls showed a greater number of entries than those administered with Risp. Again, animals administered DG4.5-Risp performed no entries.

vi. Return to the undercover arm: This test, which was performed only under chronic treatment, showed no significant differences in females between animals administered Risp or DG4.5-Risp, although the difference of both with the control group was significant. In the case of males, results were similar (results not shown).

vii. Locomotion: Locomotion was measured as a parameter related to distances using the Image J. program. For all groups, differences between controls and animals administered with Risp or DG4.5-Risp were significant, whereas differences between treatments with Risp were not significant (Figures 5 and 6).

\section{viii. Sociability and Social Novelty}

A. Approach: It is more common to see a greater number of approaches in males than in females, due to their higher territorial activities. In both groups of animals, there was an increase in the
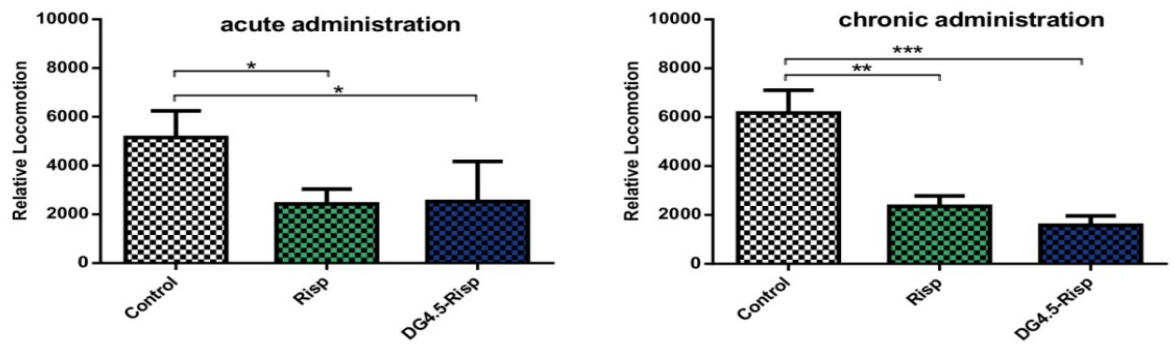

Figure 5: Locomotion. Behavioral Studies in Mice with acute and chronic administration. Relative locomotion for female mice in both the acute and chronic treatments $(n=7) .{ }^{*} p<0.05,{ }^{* \star} p<0.01,{ }^{* \star *} p<0.001$.
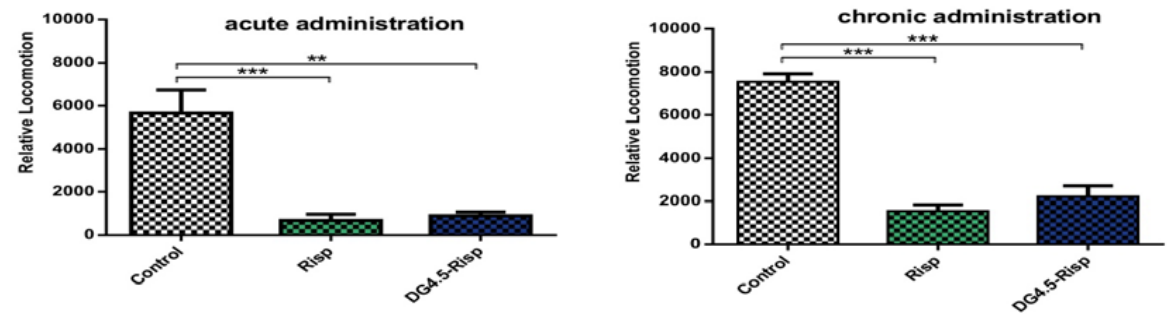

Figure 6: Locomotion. Behavioral Studies in Mice with acute and chronic administration. Relative locomotion for female mice in both the acute and chronic treatments $(n=7) .{ }^{*} p<0.05,{ }^{* *} p<0.01,{ }^{* * *} p<0.001$. 
Citation: Prieto MJ, del Rio Zabala NE, Marotta CH, Bichara D, Simonetta S, et al. (2013) G4.5 Pamam Dendrimer-Risperidone: Biodistribution and Behavioral Changes in In Vivo Model. J Nanomedine Biotherapeutic Discov 4: 121. doi:10.4172/2155-983X.1000121

Page 7 of 11

approaches of chronic versus acute group, due to habituation of animals to handling and acute treatment tests. Statistical studies showed that, for all groups, the differences between the two treatments and controls are significant. For the group of females with chronic treatment approaches the percentage for DG4.5-Risp groups is significantly less than for the free Risp. In the case of males in the two trial groups, both treatments with antipsychotic showed no differences (Figures 7 and 8).

B. Sniff: The controls of all groups significant differences compared with administered with Risp or DG4.5-Risp treatments. For acute treatments, females showed no significant differences in the number of sniffs between the two treatments. Animals administered Risp-DG4.5 showed a tendency to have fewer sniffs. Males showed no significant differences in acute treatments but there was a trend indicating less sniffing when administered the complex than when administered the free drug. For tests with chronic treatment, males and females observed significant lower number of sniffing for the group administered with the complex. The DG4.5-administered groups showed lower number of sniffs than those administered Risp, showing greater potency with chronic treatments (Figures 9 and 10).

C. Fights: Female groups showed no fights. Males in acute treatments showed that $42 \%$ of control animals clashed against $14 \%$ of animals administered Risp. None of the animals administered DG4.5Risp clashed. In chronic treatments, clashes percentage of the control groups was higher, but animals treated with DG4.5-Risp or Risp had no confrontations (data not shown).

D. Dominance: All groups showed significant differences between those treated with Risp or DG4.5-Risp and control groups, except females treated with Risp as compared with control under the acute treatment. Males under the acute treatment showed significant differences between Risp and DG4.5-Risp complexes. For chronic cases, no difference was observed between treatments. Females showed significant differences between treatments for both Risp and DG4.5Risp (Figures 11 and 12).

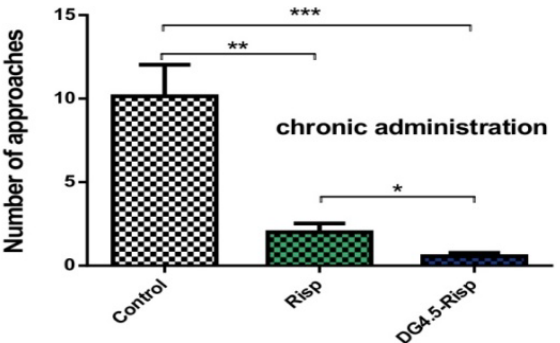

Figure 7: Sociability and Social Novelty. Approach. Number of approaches performed by female groups $(n=7) .{ }^{*} p<0.05,{ }^{* *} p<0.01,{ }^{* * *} p<0.001$.
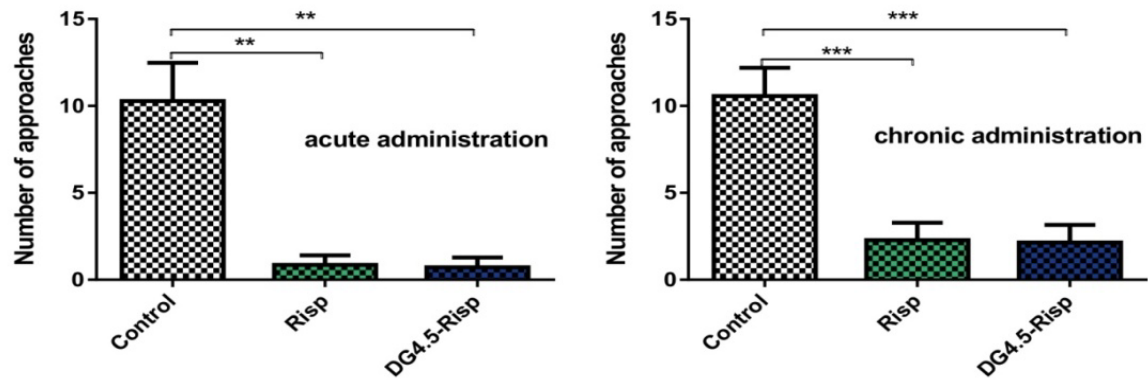

Figure 8: Sociability and Social Novelty. Approach. Number of approaches performed by males groups $(n=7) .{ }^{*} p<0.05,{ }^{* *} p<0.01,{ }^{* \star *} p<0.001$
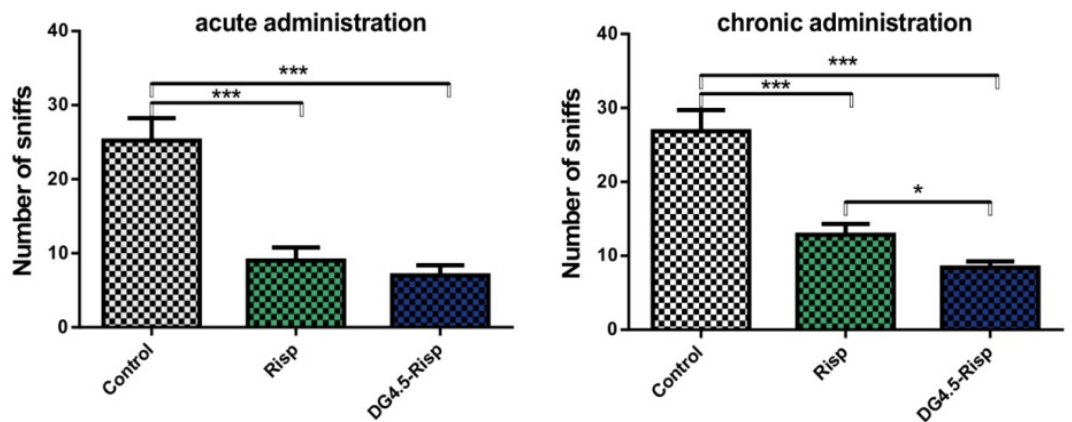

Figure 9: Sociability and Social Novelty. Sniff. Number of sniffs of female mice with an intruder in sight $(n=7) .{ }^{*} p<0.05,{ }^{* *} p<0.01,{ }^{* * *} p<0.001$. 
Citation: Prieto MJ, del Rio Zabala NE, Marotta CH, Bichara D, Simonetta S, et al. (2013) G4.5 Pamam Dendrimer-Risperidone: Biodistribution and Behavioral Changes in In Vivo Model. J Nanomedine Biotherapeutic Discov 4: 121. doi:10.4172/2155-983X.1000121

Page 8 of 11

ix. Weights: Weights were monitored daily. After 8 days of treatments in males (Risp, DG4.5-Risp or PBS), no increases or decreases were observed in weight for both treatments versus control. However, females showed a strong increase in weight when treated with the free drug, indicating a highly significant difference from the control. This increase was not observed under the treatment with DG4.5-Risp (Figures 13 and 14).

x. Nest Building: The mice administered with PBS formed a nest with far more elaboration, more compact and with more entries than those given Risp or DG4.5-Risp. All mice treated with Risp or DG4.5Risp formed nests and showed no differences in the quality of their constructions. During the resting periods, all the mice preferred nesting.

Once Risp was complexed with DG4.5, the evaluation of its effectiveness in healthy mice of both sexes was necessary. It is known that oral absorption of Risp is fast and efficient (70 to 90\%) [30], but the generation of a systemic distribution reduces the concentration of the drug in the target site and produces serious side effects.

The animals showed good health and normal behavior, so the consecutive evaluation method worked well in pursuing complete course of each trial. The handling of animals was minimal and the stress was minimized. The experimental conditions were maintained during all trials.

The previous behavioral studies in mice showed the results of complex DG4.5-Risp versus free Risp.These studies were designed in search for differences in efficacy and/or potency of the complexed drug versus the free drug. All tests showed that the potency of the DG4.5Risp was equal to or greater than that of the free Risp.

As for the weight gain, both groups of treated males showed no changes as compared to controls. However, females treated with Risp showed a strong and significant weight increase when compared to
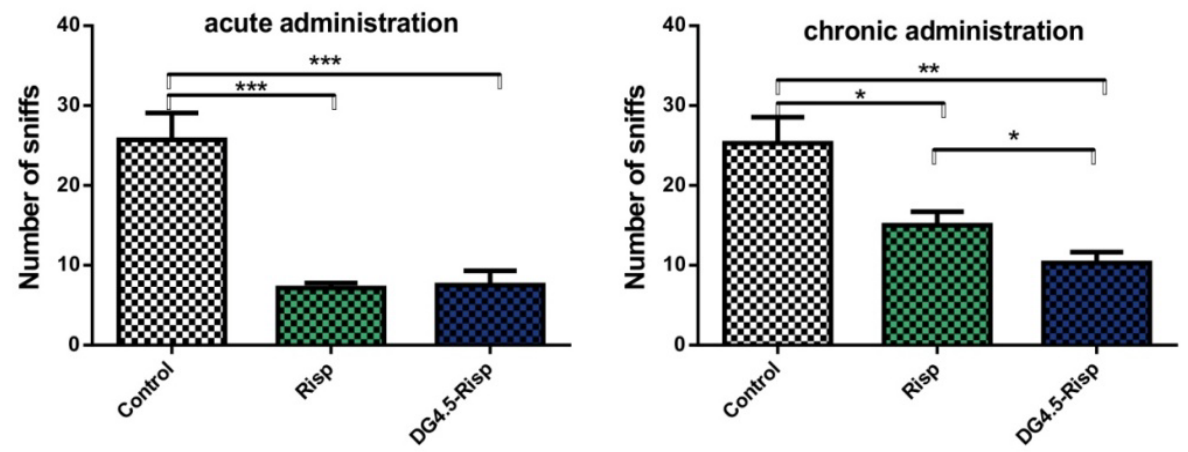

Figure 10: Sociability and Social Novelty. Sniff. Number of sniffs of male mice with an intruder in sight $(n=7) .{ }^{*} p<0.05,{ }^{* *} p<0.01,{ }^{* * *} p<0.001$.
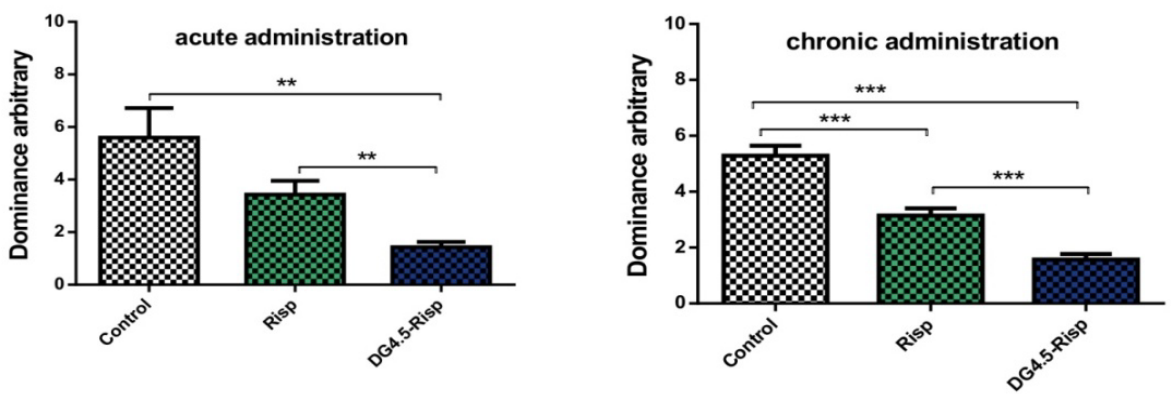

Figure 11: Sociability and Social Novelty. Dominance. Level of dominance for female mice $(n=7) .{ }^{*} p<0.05,{ }^{* *} p<0.01,{ }^{* * *} p<0.001$.
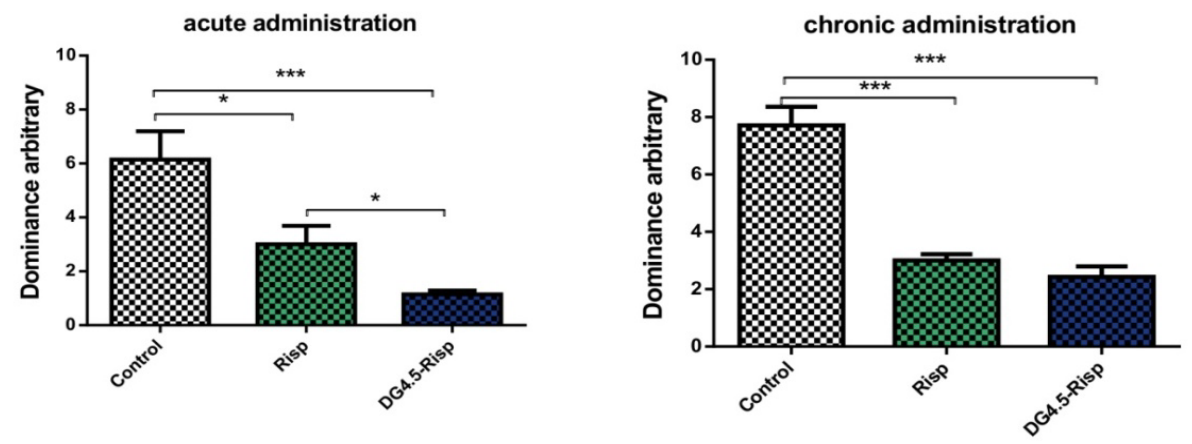

Figure 12: Sociability and Social Novelty. Dominance. Level of dominance for male mice $(n=7) .{ }^{*} p<0.05,{ }^{* *} p<0.01,{ }^{* * *} p<0.001$. 
Citation: Prieto MJ, del Rio Zabala NE, Marotta CH, Bichara D, Simonetta S, et al. (2013) G4.5 Pamam Dendrimer-Risperidone: Biodistribution and Behavioral Changes in In Vivo Model. J Nanomedine Biotherapeutic Discov 4: 121. doi:10.4172/2155-983X.1000121

Page 9 of 11

controls. This increase was not observed when treated with the DG4.5Risp complex. The weight increase in female mice was caused by the fact that Risp is related to increased levels of prolactin due to the blocking activity of the $\mathrm{D} 2$ receptors. This increase was not present when animals were given the complex.

In conclusion, we were able to modify the behavioral parameters of Risp by complexing it to DG4.5 dendrimer. The results evidenced that DG4.5-Risp complexes exert equal or greater potency than that of free Risp. On this basis, we designed an efficient drug transport by means of nanosystems. The DG4.5-Risp complex allows for non-systemic Risp distribution, higher concentration at the target site, Risp protection from enzymatic reactions, hence reducing the metabolite 9OH-RSP. The greatest achievement is that it allows lowering the doses of active Risp, hence lowering the amount of drug administered per patient with the same therapeutic effect and a marked reduction in side effects.

\section{Zebrafish behavioral studies-toxicity}

Figure 15 shows the spontaneous swimming activity of zebrafish treated with either free Risp or DG4.5-Risp. When zebrafish were treated with free Risp $25 \mu \mathrm{M}$, the swimming activity decrease significantly.
However, this decrease was not observed when treated with the same concentration of the drug complexed with DG4.5 dendrimers. A decrease in spontaneous swimming is usually considered as a factor indicating fish toxicity $[22,36,37]$. Hence, the beneficial effect of dendrimers is to decrease Risp toxicity.

\section{Conclusions}

We first studied the biodistribution and pharmacokinetics of Risp and DG4.5-Risp given orally to healthy BALB/C mice. Risp plasma concentration at any time post-treatment was significantly lower in mice subjected to DG4.5-Risp than in mice administered the free Risp. The addition of the drug to the dendrimers allowed the drug to reach the brain 90 minutes after the treatment. The behavioral studies performed in mice indicated that the complex had a power equal to or greater than commercial Risp. Body weight did not increase in treated females. On the other hand, we used the zebrafish (Danio rerio) as a model to study toxicity and other related fields of biomedicine $[13,38$ 41]. When the drug was complexed to dendrimers, toxicity decreased. $9 \mathrm{OH}-\mathrm{RSP}$ has pharmacological activity and is responsible for many of the side effects of the drug, along with weight gain and hyperprolactinemia in females [34,35].
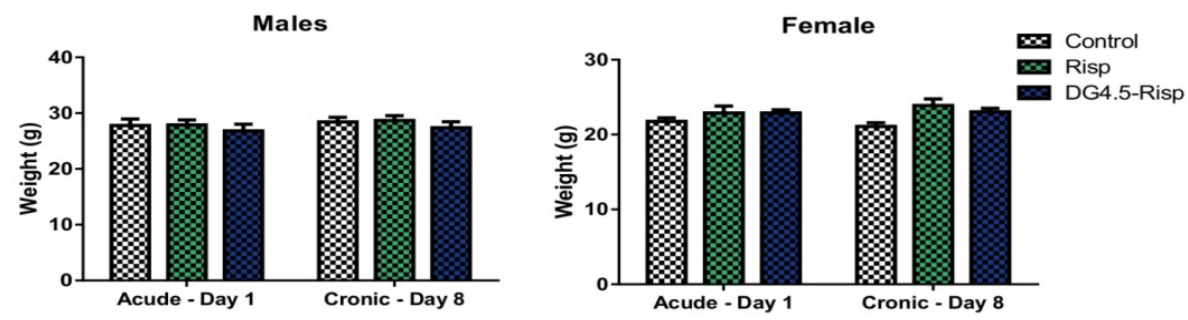

Figure 13: Weight comparison for males and females for day 1 and day 8 of the treatment $(n=7)$.
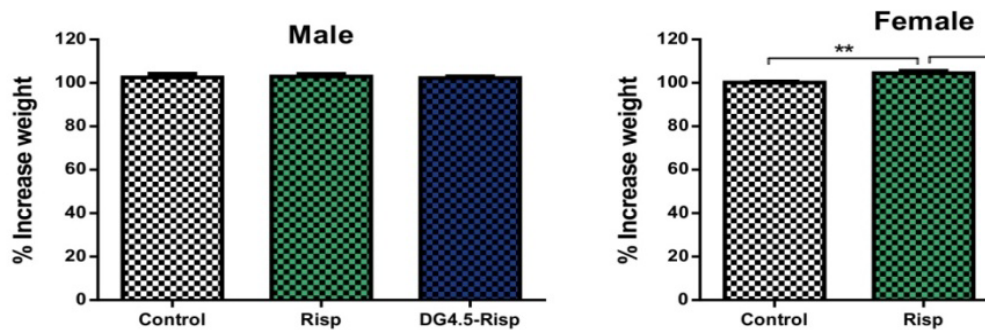

Figure 14: Weight increase for day 1 and day 8 of the treatment. The value $100 \%$ represents the weight at beginning of the treatment $(n=7) .{ }^{*} p<0.05,{ }^{* *} p<0.01$.
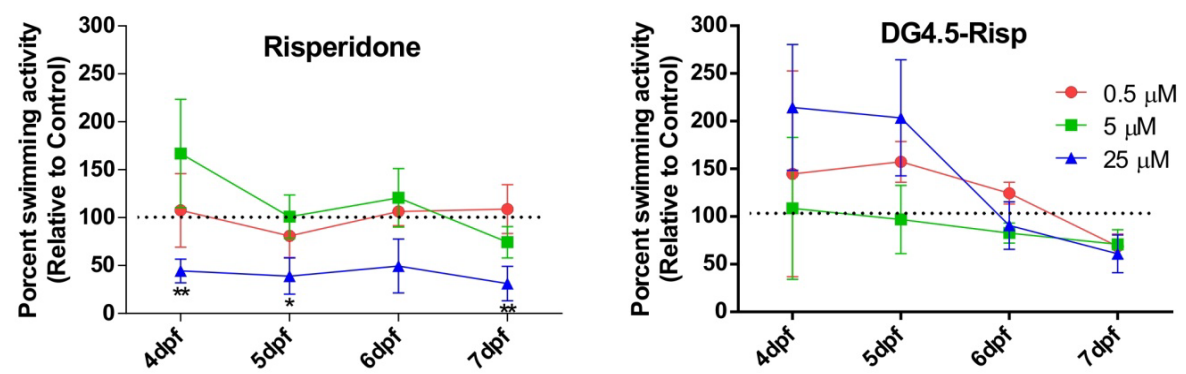

Figure 15: Zebrafish Behavioral Studies - Toxicity. Percentage of swimming activity vs control. The value $100 \%$ corresponds to control $(n=12) .{ }^{*} p<0.05,{ }^{*}$ p $<0.01$. 
Citation: Prieto MJ, del Rio Zabala NE, Marotta CH, Bichara D, Simonetta S, et al. (2013) G4.5 Pamam Dendrimer-Risperidone: Biodistribution and Behavioral Changes in In Vivo Model. J Nanomedine Biotherapeutic Discov 4: 121. doi:10.4172/2155-983X.1000121

Page 10 of 11

The addition of Risp to dendrimers to generate a complex DG4.5Risp protects the drug from enzymatic metabolism of $9 \mathrm{OH}-\mathrm{RSP}$. We have previously in Prieto et al. [8] reported the strategy followed to obtain complexes of SDZ-DG4 and SDZ-DG4.5 and found a reduced metabolism of SDZ by enzymes such as NAT and CYP2C8/9 [8]. This dendrimer protection may significantly reduce the generation of hydroxylated and/or acetylated enzymatic toxics, thereby decreasing the toxicity of the drug. Results demonstrate that the dendrimerization of the drug generates an efficient nanotransport system, less toxic than a greater amount of Risp reaching the target site of action and above all with a lower concentration of the drug in blood. This decrease in side effects and toxic metabolites increases the therapeutic action of the drug in the brain.

\section{Acknowledgment}

This research was supported by a grant from Universidad Nacional de Quilmes (Buenos Aires, Argentina). Silvia del Valle Alonso is a member of Consejo Nacional de Investigaciones Científicas y Técnicas (CONICET, Argentina) and IMBICE CICPBA (Provincia de Buenos Aires, Argentina). M.J. Prieto acknowledges fellowships from CONICET, Argentina. We thank Angel Jones and Dr. Nora Viziol of the Faculty of Pharmacy and Biochemistry, University of Buenos Aires. We would also like to thank Sebastian Graziati of Institute of Molecular and Cellular Biology of Rosario (IBR), Santa Fe, Argentina, PhD Santiago Plano of Chronobiology laboratory, UNQ and Ministerio Nacional de Ciencia, Tecnología e Innovación Productiva (MINCYT) grants.

\section{References}

1. Courchesne E, Pierce K, Schumann CM, Redcay E, Buckwalter JA, et al (2007) Mapping early brain development in autism. Neuron 56: 399-413.

2. Kumar M, Misra A, Babbar AK, Mishra AK, Mishra P, et al. (2008) Intranasal nanoemulsion based brain targeting drug delivery system of risperidone. Int $J$ Pharm 358: 285-291.

3. Marshall CR, Noor A, Vincent JB, Lionel AC, Feuk L, et al. (2008) Structura variation of chromosomes in autism spectrum disorder. Am J Hum Genet 82 477-488.

4. Malone RP, Waheed A (2009) The role of antipsychotics in the management of behavioural symptoms in children and adolescents with autism. Drugs 69 : $535-548$

5. Mannens G, Meuldermans W, Snoeck E, Heykants J (1994) Plasma protein binding of risperidone and its distribution in blood. Psychopharmacology (Berl) 114: 566-572.

6. Svenson S (2009) Dendrimers as versatile platform in drug delivery applications Eur J Pharm Biopharm 71: 445-462.

7. Prieto MJ, Bacigalupe D, Pardini O, Amalvy JI, Venturini C, et al. (2006) Nanomolar cationic dendrimeric sulfadiazine as potential antitoxoplasmic agent. Int J Pharm 326: 160-168.

8. Prieto MJ, Schilrreff P, Tesoriero MV, Morilla MJ, Romero EL (2008) Brain and muscle of Wistar rats are the main targets of intravenous dendrimeric sulfadiazine. Int J Pharm 360: 204-212.

9. Prieto MJ, Temprana CF, del Río Zabala NE, Marotta $\mathrm{CH}$, Alonso Sdel $V$ (2011) Optimization and in vitro toxicity evaluation of G4 PAMAM dendrimerrisperidone complexes. Eur J Med Chem 46: 845-850.

10. Cheng Y, Li M, Xu T (2008) Potential of poly(amidoamine) dendrimers as drug carriers of camptothecin based on encapsulation studies. Eur J Med Chem 43: 1791-1795.

11. Cheng Y, Qu H, Ma M, Xu Z, Xu P, et al. (2007) Polyamidoamine (PAMAM) dendrimers as biocompatible carriers of quinolone antimicrobials: an in vitro study. Eur J Med Chem 42: 1032-1038.

12. Prieto MJ, Del RZ, Marotta NE, Carreno Gutierrez $\mathrm{CH}$, Arevalo Arevalo R, et al (2013) Optimization and in vivo toxicity evaluation of G4.5 PAMAM DendrimerRisperidone complexes. In review.

13. Kimmel CB, Ballard WW, Kimmel SR, Ullmann B, Schilling TF (1995) Stages of embryonic development of the zebrafish. Dev Dyn 203: 253-310.

14. Shen YL, WU HL, Ko WK, Wu SM (2002) Simultaneous determination of clozapine, clozapine $\mathrm{N}$-oxide, $\mathrm{N}$-desmethylclozapine, risperidone, and 9-hidroxyrisperidone in plasma by high performance liquid chromatography with ultraviolet detection. Analytica Chimica Acta 460: 201-208.

15. Zhang G, Terry AV Jr, Bartlett MG (2007) Simultaneous determination of five antipsychotic drugs in rat plasma by high performance liquid chromatography with ultraviolet detection. J Chromatogr B Analyt Technol Biomed Life Sci 856: 20-28.

16. Crawley JN (2007) Mouse behavioral assays relevant to the symptoms of autism. Brain Pathol 17: 448-459.

17. Crawley JN, Chen T, Puri A, Washburn R, Sullivan TL, et al. (2007) Socia approach behaviors in oxytocin knockout mice: comparison of two independent lines tested in different laboratory environments. Neuropeptides 41: 145-163.

18. Silverman JL, Tolu SS, Barkan CL, Crawley JN (2010) Repetitive self-grooming behavior in the BTBR mouse model of autism is blocked by the mGluR5 antagonist MPEP. Neuropsychopharmacology 35: 976-989.

19. Silverman JL, Turner SM, Barkan CL, Tolu SS, Saxena R, et al. (2011) Sociability and motor functions in Shank1 mutant mice. Brain Res 1380: 120-137.

20. Bult A, Lynch CB (1997) Nesting and fitness: lifetime reproductive success in house mice bidirectionally selected for thermoregulatory nest-building behavior. Behav Genet 27: 231-240.

21. Moretti P, Bouwknecht JA, Teague R, Paylor R, Zoghbi HY (2005) Abnormalities of social interactions and home-cage behavior in a mouse model of Rett syndrome. Hum Mol Genet 14: 205-220.

22. Bichara D, Calcaterra NB, Arranz S, Armas P, Simonetta SH (2013) Set-up of an infrared fast behavioral assay using zebrafish (Danio rerio) larvae, and its application in compound biotoxicity screening. Journal of applied toxicology.

23. Simonetta SH, Golombek DA (2007) An automated tracking system for Caenorhabditis elegans locomotor behavior and circadian studies application. J Neurosci Methods 161: 273-280.

24. Fischer D, Li Y, Ahlemeyer B, Krieglstein J, Kissel T (2003) In vitro cytotoxicity testing of polycations: influence of polymer structure on cell viability and hemolysis. Biomaterials 24: 1121-1131.

25. Mecke A, Uppuluri S, Sassanella TM, Lee DK, Ramamoorthy A, et al. (2004) Direct observation of lipid bilayer disruption by poly(amidoamine) dendrimers. Chem Phys Lipids 132: 3-14.

26. DomaÅski DM, Klajnert B, Bryszewska M (2004) Influence of PAMAM dendrimers on human red blood cells. Bioelectrochemistry 63: 189-191.

27. Klajnert B, Bryszewska M (2002) Fluorescence studies on PAMAM dendrimers interactions with bovine serum albumin. Bioelectrochemistry 55: 33-35.

28. Han M, Chen P, Yang X (2005) Molecular dynamics simulation of PAMAM dendrimer in aqueous solution. Polymer 46: 3481-3488.

29. Withers JR, Aston DE (2006) Nanomechanical measurements with AFM in the elastic limit. Adv Colloid Interface Sci 120: 57-67.

30. Ereshefsky L, Lacombe S (1993) Pharmacological profile of risperidone. Can J Psychiatry 38 Suppl 3: S80-88.

31. Wiwattanapatapee R, Carreño-Gómez B, Malik N, Duncan R (2000) Anionic PAMAM dendrimers rapidly cross adult rat intestine in vitro: a potential oral delivery system? Pharm Res 17: 991-998

32. Florence AT, Sakthivel T, Toth I (2000) Oral uptake and translocation of a polylysine dendrimer with a lipid surface. J Control Release 65: 253-259.

33. Fang J, Bourin M, Baker GB (1999) Metabolism of risperidone to 9-hydroxyrisperidone by human cytochromes P450 2D6 and 3A4. Naunyn Schmiedebergs Arch Pharmacol 359: 147-151.

34. Canitano R, Scandurra V (2011) Psychopharmacology in autism: an update. Prog Neuropsychopharmacol Biol Psychiatry 35: 18-28.

35. Melkersson KI (2006) Prolactin elevation of the antipsychotic risperidone is predominantly related to its 9-hydroxy metabolite. Hum Psychopharmacol 21 529-532.

36. Airhart MJ, Lee DH, Wilson TD, Miller BE, Miller MN, et al. (2007) Movement disorders and neurochemical changes in zebrafish larvae after bath exposure to fluoxetine (PROZAC). Neurotoxicol Teratol 29: 652-664.

37. Prieto MJ, Gutierrez HC, Arévalo AR, Chiaramoni NS, Alonso SDV (2012) Effect of Risperidone and Fluoxetine on the Movement and Neurochemical Changes of Zebrafish. Open Journal of Medicinal Chemistry 2: 129-138. 
Citation: Prieto MJ, del Rio Zabala NE, Marotta CH, Bichara D, Simonetta S, et al. (2013) G4.5 Pamam Dendrimer-Risperidone: Biodistribution and Behavioral Changes in In Vivo Model. J Nanomedine Biotherapeutic Discov 4: 121. doi:10.4172/2155-983X.1000121

38. Chakraborty C, Hsu CH, Wen ZH, Lin CS, Agoramoorthy G (2009) Zebrafish: a complete animal model for in vivo drug discovery and development. Curr Drug Metab 10: 116-124.

39. Hu YL, Qi W, Han F, Shao JZ, Gao JQ (2011) Toxicity evaluation of biodegradable chitosan nanoparticles using a zebrafish embryo model. Int $\mathrm{J}$ Nanomedicine 6: 3351-3359.
40. McGrath P, Li CQ (2008) Zebrafish: a predictive model for assessing druginduced toxicity. Drug Discov Today 13: 394-401.

41. Peterson RT, Macrae CA (2012) Systematic approaches to toxicology in the zebrafish. Annu Rev Pharmacol Toxicol 52: 433-453.
Citation: Prieto MJ, del Rio Zabala NE, Marotta CH, Bichara D, Simonetta S et al. (2013) G4.5 Pamam Dendrimer-Risperidone: Biodistribution and Behavioral Changes in In Vivo Model. J Nanomedine Biotherapeutic Discov 4: 121 doi:10.4172/2155-983X.1000121
Submit your next manuscript and get advantages of OMICS Group submissions

Unique features:

- User friendly/feasible website-translation of your paper to 50 world's leading languages

Audio Version of published paper

Digital articles to share and explore

Special features:

- 300 Open Access Journals

25,000 editorial team

21 days rapid review process

Quality and quick editorial, review and publication processing

Indexing at PubMed (partial), Scopus, DOAJ, EBSCO, Index Copernicus and Google Scholar etc

- Sharing Option: Social Networking Enabled

- Authors, Reviewers and Editors rewarded with online Scientific Credits

- Befter discount for your subsequent articles

Submit your manuscript at: www.editorialmanager.com/pharma 